MICROBIOLOGY, Volume 167, Issue 1, 2021, Article number 001030 DOI:10.1099/mic.0.001030

PAPER TYPE: Invited (by Microbiology Society) "Personal View”

\title{
Redefining soil health
}

\section{AUTHORS: Mark Pawlett, Jacqueline Ann Hannam, Jerry W Knox}

AFFILIATION (all authors): Cranfield University, Cranfield, Bedfordshire, MK43 OAL, UK

CORRESPONDING AUTHOR: Dr M Pawlett (m.pawlett@cranfield.ac.uk) ORCiD ID:

- Pawlett: 0000-0001-8060-0345

- Hannam: 0000-0001-6661-3537

- Knox: 0

Conflicts of interest: None

KEYWORDS: agriculture; ecosystems; land management 


\section{Soil health or soil quality?}

Describing the health of complex systems requires the inclusion of interactions, both within the system and with its environment. Definitions of human health incorporate the quality of life, physical, mental and social well-being, and the absence of disease (1). For soils, the term "soil quality" (2) has largely been replaced by "soil health"; yet, these terms are often used interchangeably without clear context or definition. The main difference in definition is that "soil quality" typically uses indicators of soil condition for specific individual traits or functions (such as crop yield), similar to a 'quality of life' indicator. In contrast, "soil health" encompasses benefits to wider ecosystem services within a more holistic approach, and as such considers multiple functions and their interactions in an ecological context. Many use variants of Doran's $(3,4)$ definition, which describes soil health as "the capacity of a living soil to function, within natural or managed ecosystem boundaries, to sustain plant and animal productivity, maintain or enhance water and air quality, and promote plant and animal health"; thereby including multiple ecosystem functional traits, or "services" in addition to yield. Soil health is now a major environmental criterion for the sustainable management of soils used by policy makers in the UK (5). However, providing greater clarity on definition is both timely and important, given that the term tries to explain complex environmental systems and interactions to different stakeholders with different perspectives relating to sustainable land and environmental management.

\section{What do soils do?}

Soil functions are intrinsically dynamic processes, many of which necessitate biological interactions that are sensitive to management strategies (6). Functional traits include food crop production, carbon transformation and regulation processes, nutrient cycling processes, soil structure and stability, biodiversity and biological population regulation (soil food webs), soil water fluxes, and regulation of soil and water pollutants. A healthy soil encompassing multiple functional traits is required for a healthy ecosystem, and subsequently the delivery of ecosystem services and goods required by society. Healthy soils are biodiverse and resilient to perturbation (7), with efficient energy and nutrient flows that are often unique to ecosystems. Complexity, natural variability and ecosystem boundaries can also change due to multiple anthropogenic stresses and disturbances (e.g. climate shocks and weather extremes). Definitions thus need to consider ecosystem complexity, whilst also reflecting emergent soil properties and adaptability in changing systems. As boundaries shift, management practices to maintain specific ecosystem services may not be sustainable and/or suitable.

\section{Towards a definition and measurement of soil health}

Soil health can be defined as the capability of soils to deliver multiple functional traits required to maintain ecosystem stability within environmental constraints. This recognises that healthy soils are dynamic and able to adapt to environmental fluctuations to maintain their functional capacity. Anthropogenic influence is likely to reduce the capacity of soils to deliver multiple functions if they are managed for the delivery of single traits e.g. crop yield. Traits for specific ecosystems that are valued by society will vary between ecosystems, land use types, and societal expectations. Furthermore, not all soil functional traits can be delivered simultaneously; for example, 
the provision of food crops and water storage is difficult unless crops are grown that are both suited to the ecosystem and environment.

Assessments of soil health should thus consider multiple functional traits that are deliverable by the identified ecosystem type. The majority of commercially available soil health assessments focus solely on crop production attributes (single functional trait: soil quality). Soil physical, chemical and biological parameters should also be represented to support improved decision-making. In particular, the soil biological component is nearly always inadequately represented and/or absent in many approaches or soil management tools. In many cases the microbial analyses used in these metrics (e.g. biomass, fungal bacteria ratios, microbial community composition) are not specifically linked to clear interpretations for 'soil health'. There is thus a need to better link specific soil characteristics with function for developing a more holistic approach to measuring soil health. Various soil health scorecard systems are also currently under development, which attempt to combine multiple parameters. However, a knowledge gap in devising ecosystem specific indexes and scorecard systems that effectively describe either soil quality and/or soil health still remains. For these scorecard approaches to be accepted within the agricultural sector and applicable for practitioners in support of farm-scale decision-making, long-term field trials across different soil and climate zones are required to provide the necessary data to identify and critically evaluate the most effective indicators (8).

The use of molecular biology for describing the soil microbiome has advanced significantly since the development of the Polymerase Chain Reaction (PCR) in 1983 by Kary Mullis for DNA analysis. Quantitative PCR methodologies are now commonplace in many laboratories. Next Generation Sequencing (NGS) has evolved such that it is now possible to describe the entire soils genome DNA and RNA, thus allowing the quantification and functional association of all prokaryote, eukaryote and archaea in soil. Yet more work is needed on standardisation of methods, developing context/location specific assessments of change (as there is high temporal and spatial heterogeneity) so that specific metrics for soil health can emerge from DNA-based analyses (9).

\section{Monitoring soil health}

Soil health parameters should reflect soil functions, be sensitive to changes in land management, and be measurable within reasonable time and resource constraints (10-12). Evidence (13) suggests that farmers often favour the term soil health as it incorporates in-field assessments that often includes expert qualitative judgements (e.g. visual soil assessment, earthworm counts, soil depth, infiltration rates) combined with quantitative descriptors (organic matter, $\mathrm{pH}$, bioavailable nutrients, microbial biomass). This is fundamentally important as farmers embed valuable local experiential knowledge of their particular soil types into their land management practices. Describing healthy soil thus enables the land manager to engage with their soils, and to move beyond the view of soil existing purely to support primary crop production but to underpin multiple ecosystem services (functions). Sequencing of the soil microbiome at the species level does require the use of expensive technologies; and data complexity is substantial. However, costs are gradually reducing as laboratory and data analysis technologies evolve. Linking specific keystone species to 
functional traits and land management practices may be optimistic but increasingly possible. Better farmer engagement and co-production of soil health assessments will also facilitate longer-term in-depth analysis of soils. This improves understanding of changes related to natural and anthropogenic disturbance, and the benefits of farming innovations and risk prevention. Defining the critical triggers or 'thresholds' whereby soil becomes either "healthy" (or not) remains an on-going contested space both within academia and industry (8).

\section{Summary and Recommendations}

The term "soil health" is increasingly being used by stakeholders, but is repeatedly confused with the term "soil quality". Here we propose a definition that we believe provides greater clarity and simplification. Healthy soils have evolved through millennia due to interactions of the soils abiotic and biotic components, and their environment. The result being the development of healthy soils within a stable ecosystem with efficient nutrient and energy flows. Disturbing soils by managing for one function often restricts additional functions of a given soil type, and thus soils become degraded with loss of critical soil characteristics such as organic matter and biodiversity. This is particularly apparent when the management strategy, and ecosystem services that we are expecting the soils to deliver, contravenes natural processes. For example, arable farming on peaty soils has inevitable consequences for soil organic matter, biodiversity, and water holding capacity.

Managing soils to improve soil health also necessitates a mind-set shift such that farmers, as the custodians of our soils, are incentivised to manage soils through consideration of the landscape, ecosystem, and soil type rather than just for biomass (food) production. We see this approach as vital to meet national policy targets such as the UK Government's net-zero carbon target for 2050. Innovative land management strategies, such as rewilding $(14,15)$, regenerative agriculture (16), innovative rotations (e.g. incorporating animals into the rotation cycle), nutrient management (such as synchronising nutrient release to plant needs) may allow our soils to recover. Another promising but relatively unexplored technology is the use of novel biostimulants (materials made up of substances and/or micro-organisms) to promote rhizosphere function by stimulating natural processes to enhance nutrient uptake and increase tolerance to environmental stress. We strongly contend that managing soils in a more natural and holistic way will provide multiple societal benefits including improved soil structure, carbon sequestration (moving from carbon source to sink), biodiversity, food resilience, and ultimately enhancing human wellbeing.

\section{Funding Information}

This work was supported by the Higher Education Innovation Fund (HEIF).

\section{Conflicts of Interest}

Authors declare that there were no conflicts of interest.

\section{References}

1. WHO. World Health Organisation [Internet]. 2020 [cited 2020 Oct 21]. Available from: https://www.who.int/about/who-we-are/constitution

2. Karlen DL, Mausbach MJ, Doran JW, Cline RG, Harris RF, Schuman GE. Soil 
quality: a concept, definition, and framework for evaluation. Soil Sci Soc Am J. 1997;61:4-10.

doi:10.2136/sssaj1997.03615995006100010001x

3. Doran JW, Sarrantonio M, Liebig MA. Soil Health and Sustainability. Vol. 56,

Advances in Agronomy. 1996. p. 1-54.

doi: 10.1016/S0065-2113(08)60178-9

4. Doran JW. Soil health and global sustainability: Translating science into practice. Agric Ecosyst Environ. 2002;88(2):119-27.

doi:10.1016/S0167-8809(01)00246-8

5. Her Majesty's Government. Environment 25 Year Plan. 2019;(Her Majesty's Government (2018) 'Environment 25 Year Plan', pp. 1-151.):1-151.

6. Norris $\mathrm{CE}$, Congreves KA. Alternative management practices improve soil health indices in intensive vegetable cropping systems: A review. Front Environ Sci. 2018;6(JUN). doi:10.3389/fenvs.2018.00050

7. Van Elsas JD, Chiurazzi M, Mallon CA, Elhottova D, Krištůfek V, Salles JF. Microbial diversity determines the invasion of soil by a bacterial pathogen. Proc Natl Acad Sci U S A. 2012;109(4):1159-64.

doi:10.1073/pnas.1109326109

8. Bünemann EK, Bongiorno G, Bai Z, Creamer RE, De Deyn G, de Goede R, et al. Soil quality - A critical review. Soil Biol Biochem. 2018 May 1;120:105-25. doi:10.1016/j.soilbio.2018.01.030

9. Fierer N, Wood SA, Bueno de Mesquita CP. How microbes can, and cannot, be used to assess soil health. Soil Biol Biochem. 2021;153(December 2020).

10. Doran JW, Parkin TB. Defining and assessing soil quality. Defin soil Qual a Sustain Environ Proc Symp Minneapolis, MN, 1992. 1994;3-21.

doi:10.2136/sssaspecpub35

11. Kibblewhite M., Ritz K, Swift M. Soil health in agricultural systems. Philos Trans R Soc B Biol Sci. 2008;363(1492):685-701.

doi: 10.1098/rstb.2007.2178

12. Bastida F, Zsolnay A, Hernández T, García C. Past, present and future of soil quality indices: A biological perspective. Geoderma. 2008;147(3-4):159-71. doi: 10.1016/j.geoderma.2008.08.007

13. Romig, D.E., Garlynd, M.J., Harris R. Farmer-based assessment of soil quality: a soil health scorecard. In: Doran, J.W., Jones AJ, editor. Methods for Assessing Soil Quality: Soil Sci Soc Am Spec Publ \# 49. Madison: SSSA; 1996. p. 39-60.

doi: $10.2136 /$ sssaspecpub49.c3

14. Carroll C, Noss RF. Rewilding in the face of climate change. Conserv Biol. 2020;

10.1111/cobi.13531

15. van Klink R, van Laar-Wiersma J, Vorst O, Smit C. Rewilding with large herbivores: Positive direct and delayed effects of carrion on plant and arthropod communities. PLoS One. 2020;15(1).

doi: 10.1371 journal.pone.0226946

16. Fér $M$, Kodešová R, Hroníková $S$, Nikodem $A$. The effect of 12-year ecological farming on the soil hydraulic properties and repellency index. Biologia (Bratisl). 2020;75(6):799-807. doi: $10.2478 / \mathrm{s} 11756-019-00373-1$ 
